\title{
Diamond-Blackfan anemia RPL35A: a case report
}

\author{
Colin Byron Noel[D
}

\begin{abstract}
Background: Diamond-Blackfan anemia is a rare congenital red blood cell aplasia characterized by failed erythropoiesis, congenital abnormalities in up to $50 \%$ of patients, growth retardation in up to $30 \%$ of patients, and a predisposition to malignancy. Diamond-Blackfan anemia is both clinically and genetically a heterogenous condition ranging from subtle asymptomatic erythroid abnormalities to non-immune hydrops fetalis. Current treatment options include corticosteroid therapy, chronic red blood cell transfusions, and hematopoietic stem cell transplantation with gene therapy receiving recent attention. We report the first documented case of DiamondBlackfan anemia in a Caucasian girl secondary to a sporadic heterozygous whole gene deletion in RPL35A in South Africa. Limited resources, non-availability of tests, unfamiliarity that comes with rare diseases, an expanded differential diagnosis, and an associated neutropenia led to a delay in the diagnosis of Diamond-Blackfan anemia. This case reminds clinicians of Diamond-Blackfan anemia as a cause of aplastic anemia and highlights the difficulty and obstacles in diagnosing Diamond-Blackfan anemia in resource-limited countries.

Case presentation: We report a case of a 6-week-old Caucasian girl presenting with urosepsis and heart failure secondary to a severe anemia and neutropenia. Limited experience and resources resulted in a delay in diagnosis. Genetic studies later confirmed a heterozygous whole gene deletion of RPL35A. Initial treatment was directed toward correcting the anemia with red blood cell transfusion every 3 to 5 weeks.

Conclusion: Diamond-Blackfan anemia is a rare disease that carries significant morbidity and mortality if not diagnosed early and managed appropriately. Limited health resources, patient registries, and specialists as seen in developing countries result in a paucity of knowledge about Diamond-Blackfan anemia in Africa. This case reminds clinicians about Diamond-Blackfan anemia as a cause for anemia in infants, the limitations in making the diagnosis in under-resourced health care systems, and the need for standardized treatment protocols applicable to resourcelimited countries.
\end{abstract}

Keywords: Diamond-Blackfan anemia, DBA, Neutropenia, Bone marrow failure, Rare disease, RPL35A

\section{Background}

Diamond-Blackfan anemia (DBA) is a rare congenital red blood cell $(\mathrm{RBC})$ aplasia characterized by failed erythropoiesis, congenital abnormalities, and a predisposition to malignancy. Also known as one of the rare groups of inherited bone marrow failure syndromes, this clinically and genetically heterogeneous condition was first described by Josephs in 1936 and then as a distinct entity in 1938 by Diamond and Blackfan [1].

\footnotetext{
Correspondence: drcbnoel@gmail.com
}

Department of General / Transplant Surgery, University of Cape Town and Groote Schuur Hospital, J-Floor, Old Main Building, Observatory, Cape Town 7925, South Africa

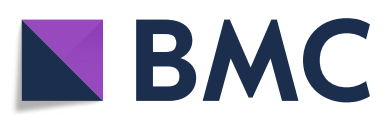

(c) The Author(s). 2019 Open Access This article is distributed under the terms of the Creative Commons Attribution 4.0 International License (http://creativecommons.org/licenses/by/4.0/), which permits unrestricted use, distribution, and reproduction in any medium, provided you give appropriate credit to the original author(s) and the source, provide a link to the Creative Commons license, and indicate if changes were made. The Creative Commons Public Domain Dedication waiver (http://creativecommons.org/publicdomain/zero/1.0/) applies to the data made available in this article, unless otherwise stated. been proposed. Traditionally, DBA was considered a ribosomopathy caused by genetic mutations in one of 19 ribosomal proteins affecting ribosome synthesis. More recently, however, three non-ribosomal gene mutations have been identified: GATA1 (an erythroid transcription factor), TSR2 (a gene encoding a direct binding partner of RPS26) [2, 3], and EPO [4]. The exact pathogenesis underlying the tissue expression in DBA and predilection for erythroid defects is not fully understood.

The characteristic hematological features of DBA include a severe normochromic macrocytic anemia, reticulocytopenia, isolated erythroid hypoplasia in the bone marrow, and an increased erythrocyte adenosine 
deaminase (eADA) [5], erythrocyte "i" antigen, and fetal hemoglobin $(\mathrm{Hb})[6]$.

The prevalence of DBA in South Africa is not currently known. Data published from international registries report an incidence of 1:100,000-200,000 live births $[7,8]$. With no known geographical variance in DBA and approximately 1,000,000 live births annually in South Africa, one can estimate between five and ten cases of children born with DBA every year. Limitations in access to children's health care and knowledge around rare diseases remain a significant challenge in developing countries and could explain the low incidence of reported cases. Although the anemia can present at any age, the median age of diagnosis is 12 weeks of age, with $90 \%$ of patients presenting with anemia within the first year [9]. It is therefore essential that DBA be considered in the workup of any infant presenting with anemia. We present the first known recorded case of DBA in South Africa.

\section{Case presentation}

A 6-week-old Caucasian girl was admitted to a private hospital in South Africa with acute onset symptomatic cardiac failure secondary to anemia. Her parents reported a 1-day history of lethargy, poor feeding, shortness of breath, and irritability on a background history of progressive pallor.

There was no family history of note. Antenatal history included a low maternal pregnancy-associated plasma protein A (PAPP-A) level $(0.376 \mathrm{IU} / \mathrm{L})$ which resulted in a high-risk screening protocol for intrauterine growth restriction (IUGR) and fetal chromosomal anomalies. Cell-free fetal deoxyribonucleic acid testing from maternal blood excluded aneuploidies for the common trisomies [10-12] and subsequent fetal anomaly ultrasound and echocardiogram scans were all normal. A caesarean section was performed at 37 weeks for spontaneous labor, IUGR, and breech presentation. The delivery was uneventful and apart from a low birth weight of $2465 \mathrm{~g}$, a healthy baby was discharged 3 days post caesarean section as per normal protocol.

On admission to hospital at 6 weeks of age, the baby under examination was severely anemic, tachycardic, and lethargic. There were no stigmata of immunocompromise, infection, or icterus. The baby weighed $3200 \mathrm{~g}$ with a head circumference of $38 \mathrm{~cm}$.

There were no obvious craniofacial or skeletal abnormalities of note and examinations of her other systems were normal. The preliminary results with normal range for age in brackets showed a hemoglobin $(\mathrm{Hb})$ level of $3.1 \mathrm{gm} / \mathrm{dL}(10-18 \mathrm{gm} / \mathrm{dL})$ and a hematocrit of 9\% (31$55 \%)$, mean corpuscular volume of $106 \mathrm{fl}(85-123 \mathrm{fl})$, mean corpuscular $\mathrm{Hb}$ concentration $34 \mathrm{~g} / \mathrm{dL}$ (32-37 g/ $\mathrm{dL})$, reticulocyte production index of 0.0 , and an absolute reticulocyte count of $5.1 \times 10^{9} / \mathrm{L}\left(20-60 \times 10^{9} /\right.$ L). Her white cell count was low $4.0 \times 10^{9} / \mathrm{L}(5-19.5 \times$ $10^{9} / \mathrm{L}$ ) but apart from a low neutrophil count of $0.32 \times$ $10^{9} / \mathrm{L}\left(1-9 \times 10^{9} / \mathrm{L}\right)$, the remaining differential count was normal. Her platelet count was increased $655 \times 10^{9} / \mathrm{L}$ $\left(140-420 \times 10^{9} / \mathrm{L}\right)$. Her C-reactive protein was marginally raised at $7.7 \mathrm{mg} / \mathrm{L}(<5 \mathrm{mg} / \mathrm{L})$, and the infective work up was positive for Escherichia coli cultured from the urine. Tests for cytomegalovirus, human immunodeficiency virus (HIV), rubella, Epstein-Barr virus, toxoplasmosis, herpes simplex virus 1 and 2, and parvovirus B19 were all negative. A diagnosis of $E$. coli urosepsis was made. The baby was transfused with leukodepleted irradiated red cell concentrate to an $\mathrm{Hb}$ level of $10 \mathrm{~g} / \mathrm{dL}$ and given goal-directed antibiotics and discharged 6 days later.

Readmission 14 days later with an anemia (Hb $7.7 \mathrm{~g} /$ $\mathrm{dL})$ and associated reticulocytopenia of $7.0 \times 10^{9} / \mathrm{L}(20-$ $60 \times 10^{9} / \mathrm{L}$ ) prompted a provisional diagnosis of transient erythroblastopenia of childhood (TEC), which was made after infection, HIV, and tuberculosis were excluded. Three further admissions over the next 3 months for anemia requiring red cell transfusions and a persistent neutropenia prompted a bone marrow biopsy (Figs. 1 and 2).

Review of the bone marrow biopsy showed reactive features with markedly increased megakaryopoiesis and significant lymphocytic infiltrate. Flow cytometry demonstrated the infiltrate to consist of $\mathrm{T}$ cells, mature $\mathrm{B}$ cells, and hematogones. An absence of red cell precursors and immunohistochemical glycophorin stain on the bone marrow trephine confirmed a pure red cell aplasia.

Due to the unavailability of molecular and eADA testing in South Africa, specimens for molecular testing were sent to Oxford, UK, for identification of a possible heterozygous pathogenic variant in one of the genes associated with DBA. A multigene panel using the

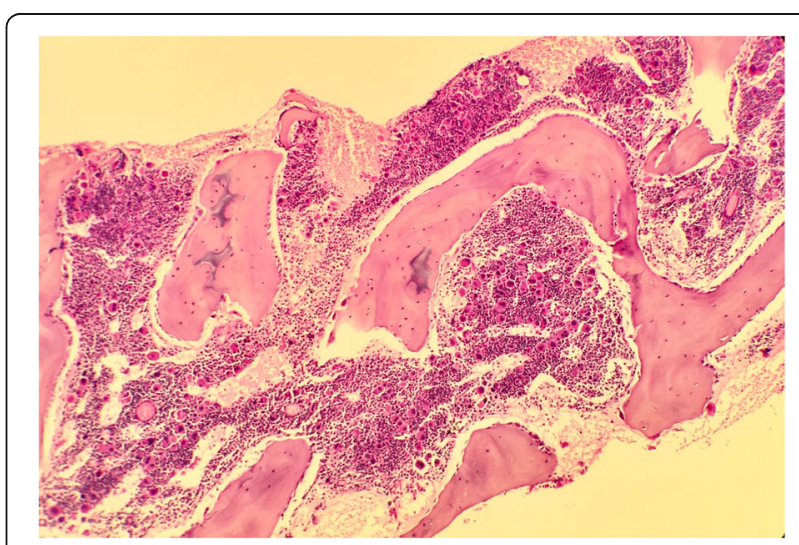

Fig. 1 Bone marrow trephine hematoxylin and eosin stain. Normocellular trephine showing normal megakaryopoiesis and granulopoiesis 


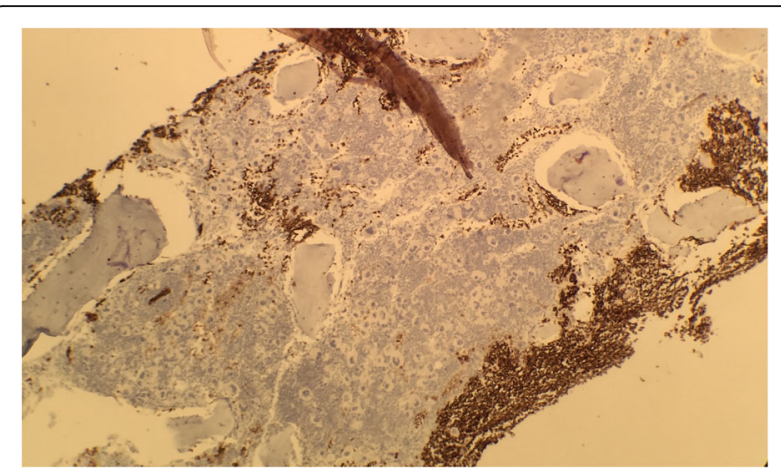

Fig. 2 Bone marrow glycophorin. Absence of red blood cell precursors

Multiplex Ligation-dependent Probe Amplification kit (MRC-Holland) confirmed a heterozygous whole gene deletion of RPL35A. In addition, dried plasma was sent to Duke University Medical Center, USA, to exclude adenosine deaminase 2 deficiency.

Once the diagnosis of DBA was made, the nonstandardized management and limited experience in managing DBA in South Africa resulted in inconsistencies in opinion in the optimal early management of the case. Controversies around $\mathrm{Hb}$ transfusion threshold, optimal $\mathrm{Hb}$ target, frequency of transfusions, and timing and dosage of corticosteroid treatment and hematopoietic stem cell transplantation (HSCT) resulted in different opinions from different specialist practitioners.

Together with input from international DBA specialists managing large numbers of patients with DBA, the initial hematopoietic management in this case was directed toward correcting the anemia with transfusions every 3-5 weeks with irradiated leukodepleted RBC concentrate. A transfusion threshold of $8 \mathrm{~g} / \mathrm{dL}$ was used and a volume of $10-15 \mathrm{ml} / \mathrm{kg}$ transfused on each visit. Planned iron chelation therapy to prevent transfusional hemosiderosis will be delayed until approximately $170-200 \mathrm{ml} / \mathrm{kg}$ of transfused red packed cells has been given. A planned trial of corticosteroids will be given at 1 year of age.

At follow-up at 6 months of age, the baby was stable requiring red cell concentrate infusion therapy every $3-$ 4 weeks. Persistence in the neutropenia was noted, with no changes in the other cell lineages. Her current ferritin level is $573 \mu \mathrm{g} / \mathrm{L}$ and a total of $90 \mathrm{ml} / \mathrm{kg}$ of red packed cells has been transfused, thus, iron chelation therapy has not yet been instituted. Apart from a delay in gross motor development and growth (weight and height), all other parameters and development are within normal limits.

\section{Discussion}

DBA is a rare cause of aplastic anemia and the main differential diagnosis of anemia due to decreased $R B C$ production includes TEC, infections, and other genetic causes of bone marrow failure. These are, however, usually associated with additional cytopenias and include Shwachman-Diamond syndrome, Fanconi's anemia, dyskeratosis, and Pearson marrow pancreas syndrome. Other acquired causes include aplasia associated with viral infections, drugs, autoimmune conditions, malignancies, and, rarely in adults, a thymoma should be considered [13].

RPL35A is a gene that encodes a $60 \mathrm{~S}$ large ribosomal subunit protein and accounts for $3.3 \%$ of cases of DBA identified with a gene mutation [6]. It was described by Farrar et al. [14] in 2008 and was the first large ribosomal subunit protein defect directly linked to DBA in humans. Although a pure red cell aplasia is typical of DBA, RPL35A mutations may have an associated neutropenia [9]. To date, mutations in 19 ribosomal genes (RPS7, RPS10, RPS15A, RPS17, RPS19, RPS24, RPS26, RPS27, RPS28, RPS29, RPL5, RPL11, RPL15, RPL18, RPL26, RPL27, RPL31, RPL35, RPL35A) and 3 nonribosomal genes (GATA1, TSR2, EPO) have been implicated in DBA [9].

The criteria used to establish the diagnosis of DBA have evolved. The current criteria proposed by Vlachos et al. [8] use clinical, histological, biochemical, and genetic parameters. Using the current proposed guidelines, there are a number of obstacles to making the diagnosis of DBA in South Africa and other countries in Africa. This is largely due to limited resources, tests, and health care services available. In addition, the historical access to health care and worker migration may influence obtaining an accurate family history about inheritance patterns of diseases. In children, TEC is the main differential diagnosis which must be excluded before making the diagnosis of DBA. Both i-RBC antigen testing and eADA activity testing which are used to differentiate TEC from DBA are not freely available in Africa. In addition, both genetic testing for DBA and eADA are not available in South Africa, and although bone marrow biopsies and histopathology are available, it is limited to a few of the larger centralized health institutions.

DBA currently has no curative treatment option. Mainstay treatment options to correct the anemia include chronic RBC transfusions, corticosteroid therapy, and HSCT $[10,15,16]$. Gene therapy, although still novel, does provide a theoretical cure to DBA. Increasing interest in gene therapy using viral vectors $[6,17]$ and novel gene editing tools CRISPR/Cas9 [18] could change current treatment protocols. Debnath et al. [6] recently reported successfully correcting the anemia in a mouse with DBA using a lentiviral vector with cellular promoters.

Current guidelines, however, are to initially treat the anemia with red cell transfusions until 1 year of age 
when a trial of steroids should be done [15]. Some authorities propose an earlier trial of steroids (6 months of age) in certain cases such as the possibility of no access to safe blood products. There are, however, concerns around growth stunting and neuromotor development with early use of corticosteroids $[19,20]$. Despite $70-$ $80 \%$ of patients initially responding to corticosteroids, only half remain on corticosteroid doses low enough to minimize toxicity [10]. Approximately $20 \%$ go into remission and the remaining $40 \%$ remain transfusion dependent [11]. Apart from corticosteroids, there are limited case reports of remission or improvement in $\mathrm{Hb}$ level using leucine $[13,21]$ or metoclopramide [12].

\section{Conclusion}

DBA although a rare cause for red cell aplasia needs to be considered in the differential diagnosis especially in infants. The diagnosis of DBA in this patient subsequently highlighted not only the difficulty in diagnosing DBA in a resource-limited setting, but also the lack of consensus in treating DBA. This case highlights the need for the establishment of a protocolized workup for infants with persistent anemia of unknown cause that includes rare genetic causes. Limited access to investigations needed to make the diagnosis of DBA using current diagnostic criteria needs to be reviewed due to the inaccessibility in Africa of some of the specialized tests. Familiarization with international treatment guidelines is important in the treatment of rare diseases but local guidelines need to be established.

Lastly, this case highlights the paucity of knowledge around DBA in Africa and the need for further research into the epidemiology of DBA in Africa and the establishment of local treatment guidelines.

\section{Abbreviations \\ DBA: Diamond-Blackfan anemia; eADA: Erythrocyte adenosine deaminase; Hb: Hemoglobin; HIV: Human immunodeficiency virus; HSCT: Hematopoietic stem cell transplantation; IUGR: Intrauterine growth restriction; RBC: Red blood cell; TEC: Transient erythroblastopenia of childhood}

\section{Publisher's Note}

Springer Nature remains neutral with regard to jurisdictional claims in published maps and institutional affiliations.

\section{Acknowledgements}

The author would like to acknowledge Dr K. Noel, Dr H. vd Watt, and Dr A. Du Pisani for their contribution.

\section{Authors' contributions}

All contributions were made by corresponding author. The author read and approved the final manuscript.

\section{Funding}

The author confirms no funding was received for the study.

\section{Availability of data and materials}

The datasets used and/or analyzed during the current study are available from the corresponding author on reasonable request.

\section{Ethics approval and consent to participate}

Due to the study design being a case report, no ethics approval was formally obtained but all correspondence was still carried out using the principles of ethical conduct as stipulated by the University of Cape Town Ethics Committee.

\section{Consent for publication}

Verbal and written informed consent was obtained from both the patient's legal guardians for publication of this case report and any accompanying images. A copy of the written consent is available for review by the Editorin-Chief of this journal.

\section{Competing interests}

The author declares that he/she has no competing interests.

Received: 11 December 2018 Accepted: 17 May 2019

Published online: 18 June 2019

\section{References}

1. Diamond LK, Blackfan K. Hypoplastic anemia. Am J Dis Children. 1938;56:464.

2. Gripp KW, Curry C, Olney AH, Sandoval C, Fisher J, Chong JX, et al. Diamond-Blackfan anemia with mandibulofacial dystostosis is heterogeneous, including the novel DBA genes TSR2 and RPS28. Am J Med Genet A. 2014;164A(9):2240.

3. Ludwig LS, Gazda HT, Eng JC, Eichhorn SW, Thiru P, Ghazvinian R, et al. Altered translation of GATA1 in Diamond-Blackfan anemia. Nat Med. 2014; 20(7):748.

4. Kim AR, Ulirsch JC, Wilmes S, Unal E, Moraga I, Karakukcu M, et al. Functional Selectivity in Cytokine Signaling Revealed Through a Pathogenic EPO Mutation. Cell. 2017;168(6):1053-64. e15

5. Fargo JH, Kratz CP, Giri N, Savage SA, Wong C, Backer K, et al. Erythrocyte Adenosine Deaminase: Diagnostic Value for Diamond-Blackfan Anaemia. Br J Haematol. 2013;160(4):547.

6. Debnath S, Jaako P, Siva K, Rothe M, Chen J, Dahl M, et al. Lentiviral Vectors with Cellular Promoters Correct Anemia and Lethal Bone Marrow Failure in a Mouse Model for Diamond-Blackfan Anemia. Mol Ther. 2017;25(8):1805.

7. Ball SE, McGuckin CP, Jenkins G, Gordon-Smith EC. Diamond-Blackfan anaemia in the U.K.: analysis of 80 cases from a 20-year birth cohort. $\mathrm{Br} J$ Haematol. 1996:94(4):645-53.

8. Vlachos A, Ball SF, N Fau D, Alter BP, Fau ABP, Sheth SF, Ramenghi UF, et al. Diagnosing and treating Diamond Blackfan anaemia: results of an international clinical consensus conference. Br J Haematol. 2008:142:859-76. JID - 0372544. 1211

9. Da Costa L, Narla A, Mohandas N. An update on the pathogenesis and diagnosis of Diamond-Blackfan anemia. F1000Research. 2018;7 https://doi. org/10.12688/f1000research.15542.1.

10. Li H, Lodish HF, Sieff CA. Critical Issues in Diamond-Blackfan Anemia and Prospects for Novel Treatment. Hematol Oncol Clin North Am. 2018;32(4):701.

11. van Dooijeweert B, van Ommen CH, Smiers FJ, Tamminga RYJ, Te Loo MW, Donker AE, et al. Pediatric Diamond-Blackfan anemia in the Netherlands: An overview of clinical characteristics and underlying molecular defects. Eur J Haematol. 2018;100(2):163.

12. Akiyama M, Yanagisawa T, Yuza Y, Yokoi K, Ariga M, Fujisawa K, et al. Successful treatment of Diamond-Blackfan anemia with metoclopramide. Am J Hematol. 2005;78(4):295.

13. Payne EM, Virgilio M, Narla A, Sun H, Levine M, Paw BH, et al. L-Leucine improves the anemia and developmental defects associated with DiamondBlackfan anemia and del(5q) MDS by activating the mTOR pathway. Blood. 2012;120(11):2214.

14. Farrar JE, Nater M, Caywood E, McDevitt MA, Kowalski J, Takemoto CM, et al. Abnormalities of the large ribosomal subunit protein, Rpl35a, in DiamondBlackfan anemia. Blood. 2008;112(5):1582.

15. Vlachos A, Muir E. How I treat Diamond-Blackfan anemia. Blood. 2010;116: 3715-23. JID - 7603509. 1216

16. Calado RT, Cle DV. Treatment of inherited bone marrow failure syndromes beyond transplantation. Hematol Am Soc Hematol Educ Program. 2017; 2017(1):96.

17. Esrick EB, Bauer DE. Genetic therapies for sickle cell disease. SeminHematol. 2018;55(2):76. 
18. Dever DP, Bak RO, Reinisch A, Camarena J, Washington G, Nicolas CE, et al. CRISPR/Cas9 beta-globin gene targeting in human haematopoietic stem cells. Nature. 2016;539(7629):384.

19. Yeh TF, Lin YJ, Huang CC, Chen YJ, Lin CH, Lin HC, et al. Early dexamethasone therapy in preterm infants: a follow-up study. Pediatrics. 1998;101(5):E7.

20. Stark AR, Carlo WA, Tyson JE, Papile LA, Wright LL, Shankaran S, et al. Adverse effects of early dexamethasone treatment in extremely-low-birthweight infants. National Institute of Child Health and Human Development Neonatal Research Network. N Engl J Med. 2001;344(2):95-101.

21. Pospisilova D, Cmejlova J, Hak J, Adam T, Cmejla R. Successful treatment of a Diamond-Blackfan anemia patient with amino acid leucine. Haematologica. 2007;92(5):e66.

Ready to submit your research? Choose BMC and benefit from:

- fast, convenient online submission

- thorough peer review by experienced researchers in your field

- rapid publication on acceptance

- support for research data, including large and complex data types

- gold Open Access which fosters wider collaboration and increased citations

- maximum visibility for your research: over $100 \mathrm{M}$ website views per year

At BMC, research is always in progress.

Learn more biomedcentral.com/submissions 